\title{
Tribological Studies of Different Bioimplant Materials for Orthopaedic Application
}

\author{
S.G. Solanke', V.R. Gaval ${ }^{2 *}$ \\ ${ }^{1}$ Department of General Engineering, Institute of Chemical Technology, Mumbai, India \\ ${ }^{2}$ Faculty of General Engineering Department, Institute of Chemical Technology, Mumbai, India
}

\begin{abstract}
This paper aims to introduce the bioimplant material by considering the tribological properties used in biomedical engineering. Sliding wear performances of four different materials like CoCrMo, SS316L, TIGR2 and TIGR5 are compared in this study. Tribological behaviour was studied considering the Specific Wear rate (SWR), coefficient of friction (COF) and the presiding wear mechanism under dry and wet conditions. The wear test was carried out to check the properties of orthopaedic bioimplant substrate materials. Our results revealed that the COF of TIGR5, TIGR2 under dry and wet test was found between the CoCrMo and SS316L. The experimental result showed that CoCrMo having less COF and SS316L having more COF compare to other bioimplant materials. After the wear test, the weight loss and SWR of CoCrMo were found to be less as compared to other materials considered in this study. The worn surface of different substrate materials was analysed with the help of SEM. In experimental graph obtained from WINDUCOM 2010 machine software, the minute fluctuation was observed in the friction curve and COF curve during the wet test.
\end{abstract}

Keywords: bioimplant materials; wear test; specific wear rate; COF; SEM

$\begin{array}{ll}\begin{array}{l}\text { Nomenclature } \\ \text { CoCrMo }\end{array} & \text { Cobalt chromium-molybdenum (ASTM F 75) } \\ \text { SS316L } & \text { Stainless Steel } 316 \mathrm{~L} \\ \text { TIGR5 } & \text { Titanium Grade } 5\left(\mathrm{Ti}_{6 \mathrm{Al}} 4 \mathrm{~V}\right) \\ \text { TIGR2 } & \text { Titanium Grade } 2 \\ \text { SEM } & \text { Scanning Electron Microscope } \\ \text { SBF } & \text { Simulated body fluid } \\ \text { SWR } & \text { Specific Wear rate } \\ \text { LWS } & \text { Loss in weight of substrate (Gram) }\end{array}$

\section{INTRODUCTION}

For improvement of research in the field of biomaterials engineering, it is necessary to study the tribological behaviour of the material to improve the existing used biomaterials otherwise for the development of new virgin materials with exceptional properties (Zivic et al., 2010). For orthopaedic implants, high quality and superior materials with reasonable cost are the demand of the 21st-century world. So generally, metals alloys are mainly preferred in the manufacturing of orthopaedic implants. Metals have biomechanical properties which made them suitable as an implant material. Besides these properties, metals are also easy to process and have a good finish. Metallic implants can be sterilized by a common sterilization procedure, which makes them easy to use (Monika et al., 2015). For safe and effective use of orthopaedic implants that are left in vivo for a long period, it is necessary to study the tribology, mechanical and biological properties of the orthopaedic bioimplant substrate material. Wear is explained as the "loss of material in particulate form as a consequence of relative motion between two surfaces" (Hallab et al., 2004). Several factors contribute to the long-term survivorship in vivo of a biomedical implant. Wear can be a major influencing factor

*Corresponding author's e-mail: vr.gaval@ictmumbai.edu.in/vg6618@gmail.com 
for the proper performance of orthopaedic bioimplant materials in an actual condition (Jones et al., 2013). Bone and bone tissue suffer substantial loads during physical activity of the human body, so it is mandatory to have a better loadbearing characteristic of artificial implants.

Load bearing orthopaedic bioimplants material like knee and hip joints are made from stainless steels or titanium alloys because of their better corrosion and mechanical properties (Park et al., 2003; Hin et al., 2004). Ti-based alloys an important bioimplant material that is generally used in total hip joint replacement. This alloys when compared with $\mathrm{Co}-28 \mathrm{Cr}-6 \mathrm{Mo}$ exhibits more wear which is primarily due to abrasion and cracking. (Choubey, et al., 2005). For better durability in the human body, the superior wear mechanism and surface modification process was suggested for orthopaedic implant material for long life and proper work functionality (Atar, 2013). Generally, the modes of failure in engineering materials are corrosion failure, fatigue failure and wear failure. The primary causes of premature failure in joint prostheses are due to wear. Joint prosthesis mostly influenced by wear failure (Chandrasekharan, 2002; Wimmer et al., 2010).

The tribological properties of material like wear rate and wear mechanism largely depends upon the manufacturing process of alloys. The heat treatment methods have more influence on the performance of bioimplant alloys (Ramadan et al., 2017). For the effectiveness of bioimplant material in the living body, it is necessary to study all aspects of bioimplant material. High and considerable wear rate is a serious problem in the orthopaedic implant. Wearing or surface rubbing between two parts leads to the production of wear debris and the metal ions may be released into the bloodstream and tissues, which may cause a serious problem. To avoid this, it is required to impart superior properties to the material (Patel et al., 2012). In the reported literature, no information is available about SWR, COF values of CoCrMo, SS316L, TIGR5 and TIGR2 materials as far as process parameters indicated in table 1 are concerned. In the present work above mentioned substrate materials have been tested as per ASTM G-99 standard for dry and wet conditions with the process parameters as indicated in Table 1.

\section{MATERIALS AND METHOD}

Wear ball on disk machine (DUCOM, Bangalore, India) was used to study the coefficient of friction (COF) and SWR of different materials. Specimen of $40 \mathrm{~mm}$ diameter and $6 \mathrm{~mm}$ thickness (Substrate material) were polished to a roughness value of 0.2 to $0.5 \mu \mathrm{m}$. Wear studies are performed on the specimen at 55 RPM with $0.1 \mathrm{~m} / \mathrm{s}$ linear speed and $200 \mathrm{~m}$ sliding distance for a track diameter of $35 \mathrm{~mm}$. A steel ball (indenter) of $8 \mathrm{~mm}$ diameter was used. The wear between the specimen and steel ball was noted by the linear variable differential transformer sensor which was mounted on the machine. The substrate materials were tested under the dry and wet conditions at $5 \mathrm{~N}$ and $10 \mathrm{~N}$ load as per the ASTM G99 standard. For wet condition, the specimen was immersed in SBF using the same test condition. The SBF is prepared using Kokubo's recipe. This solution contains various ions and has a common $\mathrm{pH}$ of 7.25, like human plasma (Kokubo et al., 1990). The process parameter for sliding wear test as presented in Table 1.

Table 1. Parameter for sliding wear test

\begin{tabular}{|l|l|}
\hline Substrate material & $\begin{array}{l}\text { SS316L, CoCrMo, } \\
\text { TIGR2, TIGR5, }\end{array}$ \\
\hline Ball material (indenter) & $8 \mathrm{~mm}$ diameter steel \\
\hline $\begin{array}{l}\text { Substrate material } \\
\text { Dimension }\end{array}$ & $\begin{array}{l}40 \mathrm{~mm} \text { diameter and } \\
6 \mathrm{~mm} \text { thickness }\end{array}$ \\
\hline $\begin{array}{l}\text { Substrate material } \\
\text { surface finish }\end{array}$ & 0.2 to $0.5(\mu \mathrm{m})$ \\
\hline Sliding speed (V) & $0.1 \mathrm{~m} / \mathrm{s}$ \\
\hline Normal load (P) & $10 \mathrm{~N}, 5 \mathrm{~N}$, \\
\hline Sliding distance & $200 \mathrm{~m}$ \\
\hline Track diameter (D) & $35 \mathrm{~mm}$ \\
\hline RPM (N) & 55 \\
\hline Time (T) & $34 \mathrm{minutes}$ \\
\hline
\end{tabular}

The weight of TIGR5 substrates is less as compared to CoCrMo, SS316L and TIGR2. The strength to weight ratio of TiGr5 is better as compared to other substrates. Strength to weight ratio is one of the important properties considered for bioimplant materials. 
Table 2. Chemical composition (\%), density (g/ $\left.\mathrm{mm}^{3}\right)$ and hardness of materials (HV)

\begin{tabular}{|c|c|c|c|c|}
\hline Material & CoCrMo & SS316 L & TIGR2 & TIGR5 \\
\hline N (Nitrogen) & - & - & $0.02 \%$ & $0.04 \%$ \\
\hline C (Carbon) & - & - & $0.1 \%$ & $0.005 \%$ \\
\hline H (Hydrogen) & - & - & $0.020 \%$ & $0.0125 \%$ \\
\hline Fe (Iron) & $0.39 \%$ & $67.28 \%$ & $0.2 \%$ & $0.3 \%$ \\
\hline O (Oxygen) & - & & $0.25 \%$ & $0.10 \%$ \\
\hline $\mathrm{Al}$ (Aluminium) & - & - & - & $5.7 \%$ \\
\hline V (Vanadium) & - & - & - & $3.89 \%$ \\
\hline Ti (Titanium) & - & - & $99.41 \%$ & $89.95 \%$ \\
\hline Mo (Molybdenum) & $5.52 \%$ & $2.03 \%$ & - & - \\
\hline Ni (Nickel) & - & $10.42 \%$ & - & - \\
\hline Co (Cobalt) & $65.19 \%$ & $1.17 \%$ & - & - \\
\hline Mn (Manganese) & $0.64 \%$ & $1.97 \%$ & - & - \\
\hline Cr (Chromium) & $28.26 \%$ & $15.45 \%$ & - & - \\
\hline \multicolumn{5}{|c|}{ Density and Hardness of materials } \\
\hline Density $\left(\mathrm{g} / \mathrm{mm}^{3}\right)$ & $8.3 \times 10^{-3}$ & $7.98 \times 10^{-3}$ & $4.51 \times 10^{-3}$ & $4.43 \times 10^{-3}$ \\
\hline Hardness (HV) & 470 & 203 & 210 & 315 \\
\hline
\end{tabular}

\section{RESULT AND DISCUSSION}

Weight loss of materials: Before the start and end of every test, the weight of substrate materials was noted by Electronic Weighing machine (Contech Instruments Ltd., Navi Mumbai, India) under the dry and wet condition at $10 \mathrm{~N}$ and $5 \mathrm{~N}$.
Weight loss of the substrate materials in grams shown in Table 3. The weight loss for the CoCrMo substrate material was found to be much lesser as compared to other materials by its hardness and observed good wear resistance as compared to other substrate materials.

Table 3. Weight loss (Gram)

\begin{tabular}{|c|c|c|}
\hline Material & LWS under Dry Test for 10 N load & LWS under Dry Test for 5 N load \\
\hline CoCrMo & 0.0005 & 0.0003 \\
\hline SS316L & 0.0035 & 0.0016 \\
\hline TIGR2 & 0.0066 & 0.0032 \\
\hline TIGR5 & 0.0055 & 0.00266 \\
\hline Material & LWS under Wet Test for 10 N load & LWS under Wet Test for 5 N load \\
\hline CoCrMo & 0.0003 & 0.00014 \\
\hline SS316L & 0.0024 & 0.0011 \\
\hline TIGR2 & 0.0054 & 0.0027 \\
\hline TIGR5 & 0.0042 & 0.0020 \\
\hline
\end{tabular}

The SWR was calculated by the following equation.

$$
w_{s}=\frac{\Delta w}{L_{s} \rho F}
$$

where $w_{s}$ denotes SWR $\left(\mathrm{mm}^{3} / \mathrm{N}-\mathrm{m}\right), w_{s}$ is the weight loss (grams), $L_{S}$ is the Sliding distance (meters), $\rho$ is the density of the worn material $\left(\mathrm{g} / \mathrm{mm}^{3}\right), F$ is the applied load or normal load (N). The CoCrMo material exhibited much less SWR. SWR of SS316L lies between CoCrMo and TIGR2, TIGR5 substrate materials. The SWR for all the four substrate materials is as shown in Table 4. 
Table 4. SWR (mm³/N-m) value for $10 \mathrm{~N}, 5 \mathrm{~N}$ under dry and wet conditions

\begin{tabular}{|l|c|c|c|c|}
\hline Material & Dry Test for $10 \mathrm{~N}$ & Dry Test for $5 \mathrm{~N}$ & Wet Test for $10 \mathrm{~N}$ & Wet Test for $5 \mathrm{~N}$ \\
\hline CoCrMo & $0.3 \times 10^{-4}$ & $0.361 \times 10^{-4}$ & $0.18072 \times 10^{-4}$ & $0.1686 \times 10^{-4}$ \\
\hline SS316L & $2.192 \times 10^{-4}$ & $2.005 \times 10^{-4}$ & $1.5039 \times 10^{-4}$ & $1.3784 \times 10^{-4}$ \\
\hline TIGR2 & $7.317 \times 10^{-4}$ & $7.095 \times 10^{-4}$ & $5.986 \times 10^{-4}$ & $5.908 \times 10^{-4}$ \\
\hline TIGR5 & $6.20 \times 10^{-4}$ & $6.004 \times 10^{-4}$ & $4.740 \times 10^{-4}$ & $4.5146 \times 10^{-4}$ \\
\hline
\end{tabular}

The graphical representation of the SWR of different substrate materials shown in Figure 1.

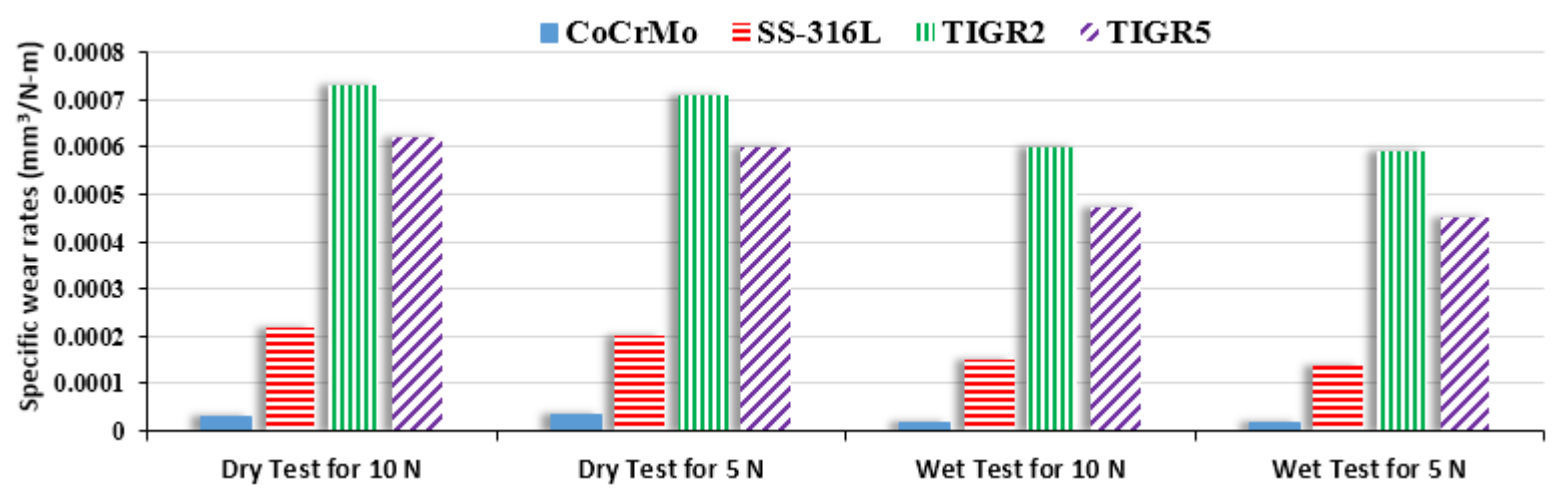

Figure 1. SWR of different substrate materials

Table 5. COF value for $10 \mathrm{~N}, 5 \mathrm{~N}$ under dry and wet conditions

\begin{tabular}{|l|c|c|c|c|}
\hline Material & Dry Test for $10 \mathrm{~N}$ & Average of COF for 10 N & Dry Test for 5 N & Average of COF for 5 N \\
\hline CoCrMo & 0.46 to 0.53 & 0.50 & 0.42 to 0.47 & 0.40 \\
\hline SS-316L & 0.70 to 0.82 & 0.76 & 0.70 to 0.80 & 0.75 \\
\hline TIGR2 & 0.56 to 0.63 & 0.60 & 0.53 to 0.61 & 0.57 \\
\hline TIGR5 & 0.54 to 0.59 & 0.56 & 0.51 to 0.57 & 0.54 \\
\hline Material & Wet Test for $10 \mathrm{~N}$ & Average of COF for $10 \mathrm{~N}$ & Wet Test for $5 \mathrm{~N}$ & Average of COF for 5 N \\
\hline CoCrMo & 0.36 to 0.41 & 0.38 & 0.34 to 0.40 & 0.37 \\
\hline SS316L & 0.57 to 0.63 & 0.60 & 0.54 to 0.62 & 0.58 \\
\hline TIGR2 & 0.47 to 0.52 & 0.49 & 0.46 to 0.52 & 0.49 \\
\hline TIGR5 & 0.42 to 0.48 & 0.45 & 0.40 to 0.47 & 0.43 \\
\hline
\end{tabular}


The average value of $\mathrm{COF}$ is obtained from the data recorded in the form of an excel sheet from the WINDUCOM 2010 machine software. Wear ball on disk machine is attached to a computer (ACER VERITON M2Oo-H81 DESKTOP, PCI-E -6321 NI Card, DUCOM, Bangalore, India) displays all the results in graphical form. The experimental values of $\mathrm{COF}$ at a load and period are given in table 5 .

The graphical representation of the range of COF values observed during the experiment for different substrate material at $10 \mathrm{~N}$ and $5 \mathrm{~N}$ load is given in Figure 2. The graph is plotted using actual data obtained from WINDUCOM 2010 machine software in the form of an excel sheet.

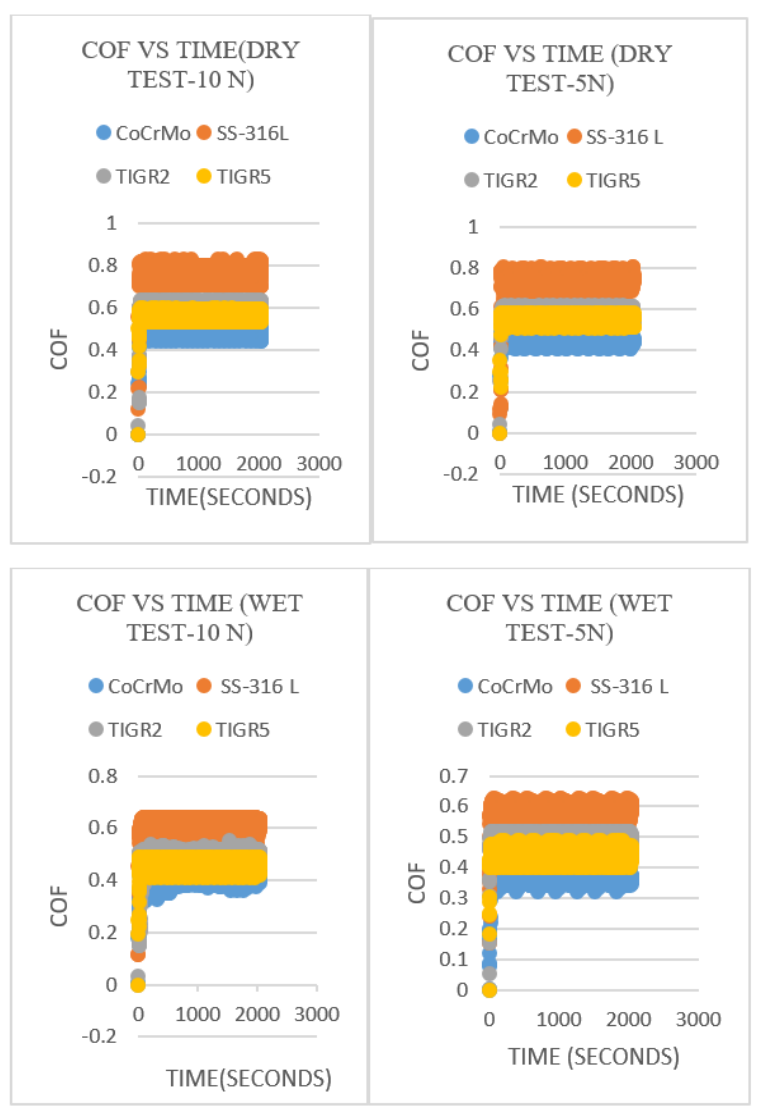

Figure 2. Range of values for COF obtained during dry and wet test

From the experimental data, it was observed that the value of COF and SWR did not change noticeably with the increasing load during both dry and wet test. Figure 4 and Figure 5 shows images from WINDUCOM 2010 software depicting variation in frictional force at various locations along the sliding path under dry and wet conditions, respectively. From the graph, it is observed that wear and COF for different substrates are found to be less during the wet test because of SBF.

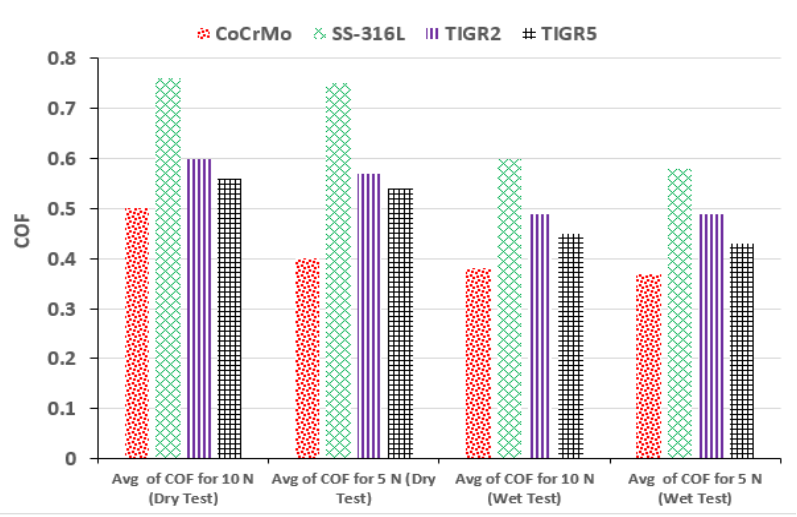

Figure 3. The average value of COF during the dry and wet test at $10 \mathrm{~N}, 5 \mathrm{~N}$

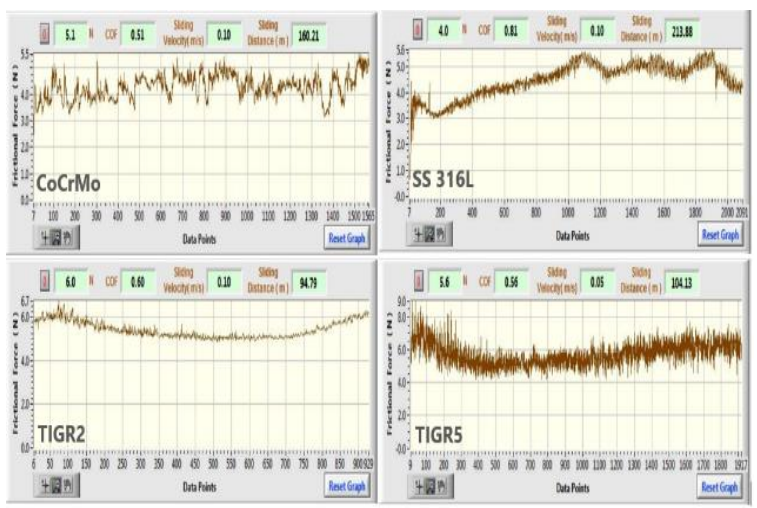

Figures 4. WINDUCOM 2010 software screen-captured images for the dry test

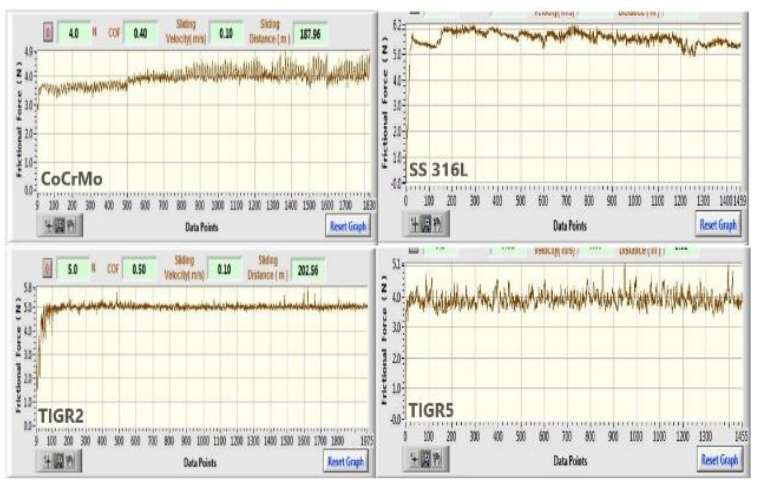

Figure 5. WINDUCOM 2010 software screen-captured images for the wet test

The considerably lower SWR and COF of the CoCrMo alloy can be associated with its higher hardness and wear resistance. The relatively higher SWR and the moderate COF of the TIGR2, TIGR5 materials can be correlated with the inherent characteristic of titanium for low shear strength and high tendency to scuffing arising from its hexagonal closed packed crystal structure. The higher resolved critical shear strength of face-centred cubic SS316L observed higher COF as compared to that of the hexagonal closed packed TIGR2, 
TIGR5 materials having a low separation between basal planes (Cvijovic et al., 2010).

SEM: Figure 6 and Figure 7 shows SEM images of different substrates under the dry and wet condition at $10 \mathrm{~N}$ and $5 \mathrm{~N}$, respectively. SEM images were taken at MMMF lab, IIT Bombay (Carls Zeiss Microscopy Ltd. Cambridge CB 1 3JS, United Kingdom). SEM images of all substrates for the dry test shows more wrinkled and rough surfaces as compared to SEM images obtained for the wet test. It may be attributed to the use of SBF during a wet test. The hardness of materials in the ascending order from high to low of CoCrMo, TIGR5, TIGR2 and SS316L. SS316L has a lesser hardness compared to other substrates material, but it exhibited better wear resistance along with higher steady-state friction coefficient than TIGR5 and TIGR2 substrate materials. Also, it observed the weight loss in SS316L is less than TIGR5 and TIGR2 materials. This is because of the formation of oxide islands during sliding contact at some locations as evident from SEM. This oxidized surfaces of SS316L get fragmented or become stable to some extent. The formed fragmented oxide layer or particles sometimes acts as a lubricating agent, and thus this oxide layer reduces weight loss [Hummel, 2004]. From SEM, the dominant wear mechanisms were identified as adhesive in the case of the wet test. Still, in the dry test, SEM images revealed some cracks, fatigue and delamination area at some location. Also, in the dry test contact surface of the counterface used in testing was more markedly darkened as compared to wet test. Although TIGR5, TIGR2 have many advantages over SS316L and CoCrMo from the viewpoints of biomedical requirements, including high strength to weight ratio, close modulus of elasticity to that of bone, and enhanced biocompatibility. These specific properties are very important in the bioimplant material. However, considering these specific properties, this study recommends the TIGR 5 and TIGR 2 materials.

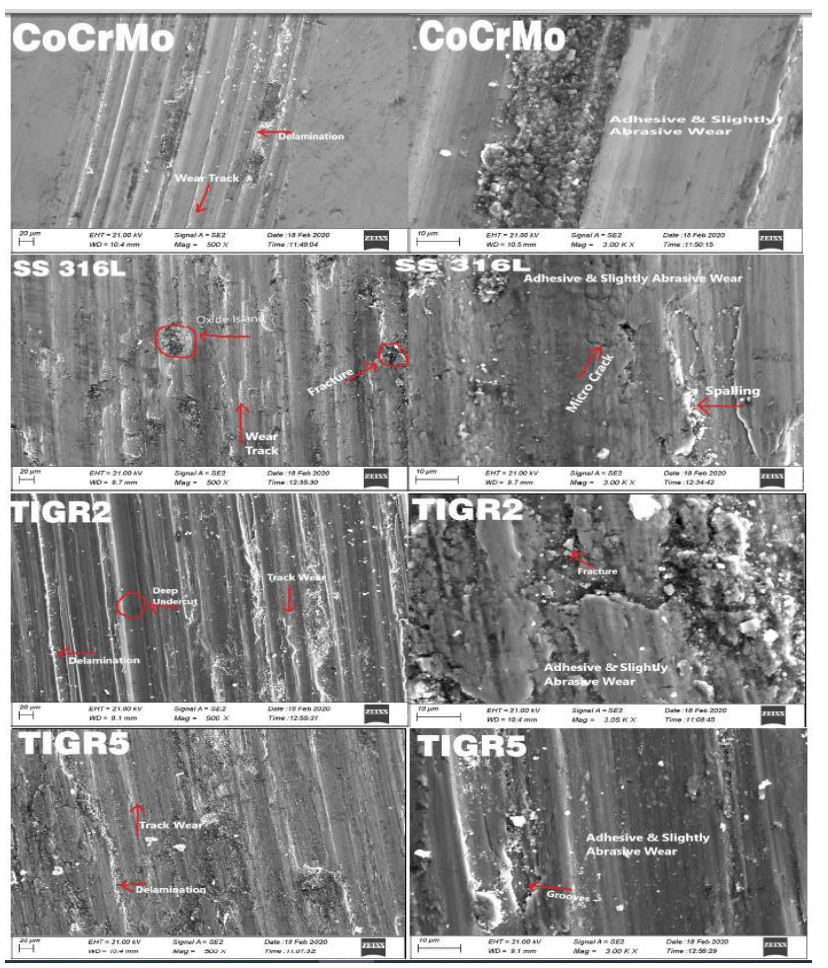

Figure 6. SEM images of different substrates during the dry test
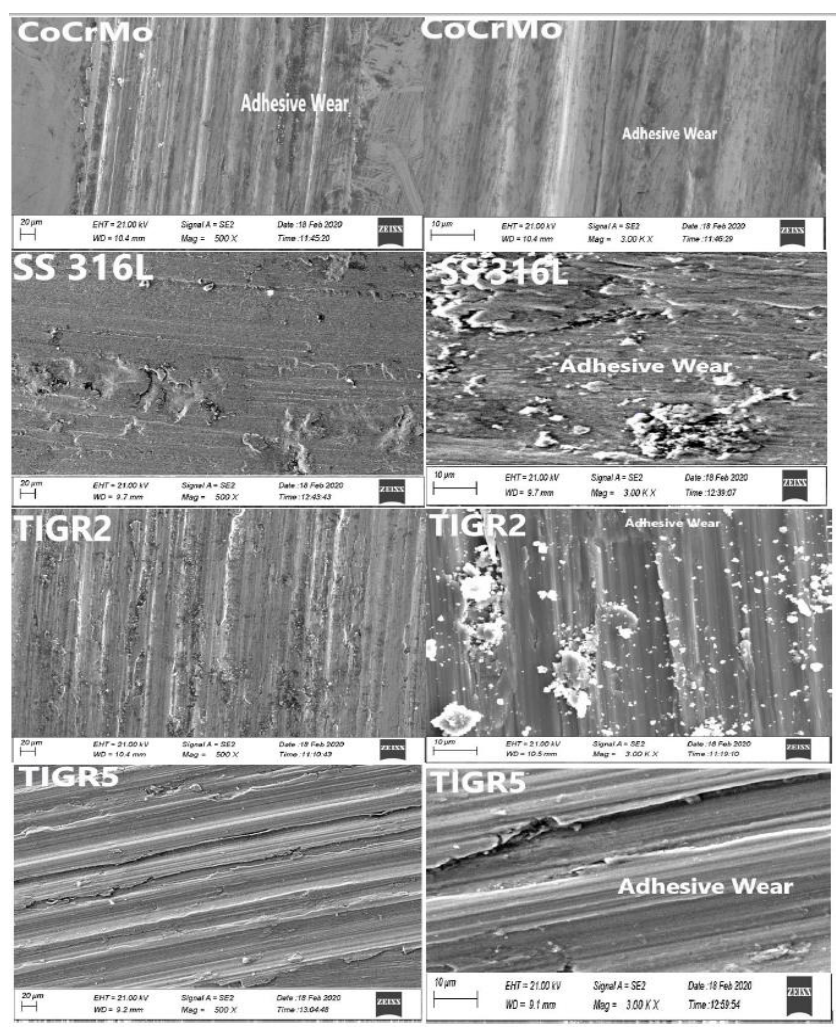

Figure 7. SEM images of different substrates during wet test 


\section{CONCLUSION}

Weight loss and SWR was found to be increasing from low to high in the ascending order of CoCrMo, SS 316L, TIGR5 and TIGR2 for all loads in the dry and wet test. Which is attributed to the hardness of substrates. However, for SS316L, despite having less hardness as compared to TIGR5. The weight loss and SWR are less than TIGR5 and TIGR2. This is because of the formation of oxide islands at some locations as evident from SEM.

COF was found to be increasing from low to high in the ascending order of CoCrMo, TIGR5, TIGR2 and SS316L for all loads in the dry and wet test.

In the case of dry test, it is evident from SEM images that mostly there is adhesive wear and at a few locations, abrasive wear was observed for all substrates. SEM images revealed the presence of areas of cracks and fractures due to plastic deformation, which is attributed to abrasive wear. However, in the case of a wet test, only adhesive wear was observed.
Tribological properties of TiGr2 and TiGr5 are marginally different. However, considering cost-effectiveness and commercial availability use of TiGr2 as bioimplant materials is suggested as an alternative to TiGr5. For the superior performance of bio implant material, this study demands the necessity of surface modification of various substrates by using different surface coating methods. Also, it is important to study the effect of surface coating and Surface topography generation process. In vitro and In vivo biocompatibility behaviour of different coated substrates needs to be investigated.

\section{REFERENCES}

Atar, E 2013, 'Sliding wear performances of $316 \mathrm{~L}$, Ti6Al4V, and CoCrMo alloys', Kovovo Materials, vol. 51, pp. 183-188. Chandrasekaran, M (eds) 2002, Materials Degradation and its Control by Surface Engineering, 2nd edn, World Scientific Publishing Co. Pte. Ltd., London, UK.

Choubey, A, Basu, B \& Balasubramaniam, R 2005, 'Tribological behavior of Ti-based alloys in simulated body fluid solution at fretting contact' Trends Biomater. Artif. Organs, vol. 18, no. 2, pp. 141-147.

Cvijovic, I, Cvijovic, Z, Mitrovic, S, Rakin, M, Veljovic, G, \& Babic, M 2010, 'Tribological Behaviour of orthopedic Ti13Nb-13Zr and Ti-6Al-4V Alloys', Tribology Letters, vol. 40, 2010, pp. 59-61.

Hallab, N, Jacobs, J \& Katz, J 2004, 'Orthopedic Applications', eds BD Ratnar, AS Hoffman, FJ Schoen \& JE Lemons, in Biomaterials Science: An Introduction to Materials in Medicine, Elsevier, San Deigo, USA, pp. 527555 .

Hin, T (eds) 2004, Engineering Materials for Biomedical Applications, 1st edn, World Scientific Publishing, London, UK.
Hummel, RE (eds) 2004, Understanding Materials Science; History, Properties and Applications, 1st edn, SpringerVerlag, New York.

Jones, L, Tsao, A \& Topoleski, L 2013, 'Factors contributing to orthopedic implant wear', Wear of orthopedic implant and artificial joints, Wear of orthopaedic implants and artificial joints, vol. 15, pp. 310-350.

Kokubu, T, Kushitani, H, Sakka, S, Kitsugi, T \& Yamamuro, T 1990, 'Solutions able to reproduce in vivo surface-structure changes in bioactive glass-ceramic', Material Research, vol. 24, pp. 721-734.

Monika, S, Yashpal, S, Pooja, A, Vipin A \& Krati, J 2015, 'Implant biomaterials: A comprehensive review', World $J$ Clin Cases, vol. 3, pp. 52-57.

Park, B \& Bronzino, J (eds) 2003, Biomaterials: Principles and Applications, 1st edn, CRC Press, New York, US.

Patel, B, Favaro, G, Inam, F, Reece, MJ, Angadji, A, Bonfield, W, Huang J \& Edirisinghe, $M$ 2012, 'Cobalt-based orthopaedic alloys: Relationship between forming route, microstructure and tribological performance', Materials, vol. 32, no. 5, pp. 1222-1229.

Ramadan, NE, Khaled, MI, Azza, FB \& Reham, RB 2017, 'Effect of Heat Treatment Processes on Microstructure and 
Mechanical Behavior of TC21 Titanium Alloy', Open Journal of Metal, vol. 7, pp. 39-57.

Wimmer, M, Fischer, A Buscher, R, Sprecher, C \& Hauert, R 2010, 'Wear mechanisms in Metal on metal bearings: The importance of tribochemical reaction layers', Journal of Orthopedic Research, vol. 28, pp. 436-444.

Zivic, F, Babic, M, Grujovic, N \& Mitrovic, S 2010, 'Tribometry of Materials for Bioengineering Applications', Tribology in Industry, vol. 32, pp. 25-32. 